\title{
People sustainability in palm oil production: the influence of production technology on workplace ambient
}

\begin{abstract}
Sustainability of the palm oil industry consists of three Ps. The first $\mathrm{P}$, the profit is the main concern of the stakeholders especially the company directors, while the other two Ps, people and planet, have frequently been manipulated by special interest group and other seed oil producers to ruin the image of palm oil industry. Workers in palm oil mills are said to be forced to work in extremely polluted and very hot working area. As one of the source of workplace pollution and heat, the production technologies developed in producing crude palm oil need to be investigated. Therefore, this article aim for two main objectives; firstly to identify the workers' level of satisfaction against their workplace ambient, focusing on three dimensions of ambient, namely the workplace air quality, workplace odour and workplace temperature. The second purpose is to compare which production technology, based on three types of sterilizer, possesses the least detrimental effect on workplace ambient. The result shows that the level of satisfaction on the three dimensions of workplace ambient is more than 4.5 out of 7 Likert scale, which implied that the workers are somehow satisfied with their workplace ambient denying the claim of extreme workplace ambient and forced labour practice in the Malaysia Government related palm oil mills. In detail, the workplace air quality satisfaction level is 4.939 , workplace odour satisfaction level is 4.538 and workplace temperature satisfaction level is 4.599 . Comparison shows that the air quality satisfaction level is significantly associated to the technology being used. The highest air quality satisfaction is associated to horizontal sterilizer followed by vertical sterilizer and continuous sterilizer is associated to the lowest ambient satisfaction. This finding explains why most mills refuse to change to new technology. In term of workplace odour and temperature satisfaction, no significant differences are found.
\end{abstract}

Keyword: Palm oil; Satisfaction; Sterilizer; Sustainability; Technology; Workplace 